\title{
Gonadoblastoma: Primary Amenorrhoea with Gonadal Dysgenesis
}

\author{
H BEGUM $^{\mathrm{a}}$, S KHATON ${ }^{\mathrm{b}}$, S JAHAN ${ }^{\mathrm{c}}$
}

\author{
Summary: \\ A seventeen year old unmarried girl presented with no \\ development of breasts and non establishment of \\ menstruation till then. She was with average height \& \\ weight, chromosome analysis was 46XY (Swyer \\ Syndrome). Laparoscopy followed by laparotomy showed
}

\section{Introduction:}

Gonadoblastoma is a rare and always a benign form of cancer. It is exclusively found in patients with an underlying gonadal disorder. It accounts for two-third of gonadal tumour in women with an abnormal karyotype $1,2,3$. Most of the cases, it is highly associated with abnormal development of the reproductive system ${ }^{3,4}$. The neoplastic nature of gonadoblastoma has been questioned because some lesions are small \& may undergo complete regression by hyalinization \& calcification 4. In 1953, gonadoblastoma was first detected in details by Scully as a gonadal tumour composed of germ cell \& sex cord derivatives 1,2. Gonadoblastoma occurs almost always in patients with pure gonadal dysgenesis with 46XY karyotype (Swyer Syndrome) ${ }^{7}$. Some times it occurs in mixed gonadal dysgenesis or in male pseudohermaphrodites ${ }^{7,8}$. Dysgerninoma occurs in $50 \%$ of patients \& it may be associated with more malignant germ cell tumours 6,7 .

\section{Case Report:}

A 17 year old unmarried girl was admitted in gynaecology \& obstetrics department of BSMMU on $12^{\text {th }}$ June, 2006 with non establishment of

a. Dr. Hamida Begum, DGO, FCPS (Gynae \& Obs), Asst. Prof., Dept. of Gynae \& Obs, BSMMU

b. Prof. Sabera Khaton, FCPS (Gynae \& Obs), Head of Oncology Unit, BSMMU

c. Prof. Sultana Jahan, Chairman \& Head of the Department (Gynae \& Obs) BSMMU

Address of correspondence: Dr. Hamida Begum, FCPS, Asst Professor, Dept. of Gynae \& Obs., BSMMU, Shahbag, Dhaka, Contact: 8750996 (landline), 01819243619 (cell), Email: hamidabgm@yahoo.com

Received: 27 August, 2007

Accepted: 3 March, 2008 irregular surfaced gonads with rudimentary uterus. Gonadectomy done \& histopathology revealed features of gonadoblastoma. She had under gone 6 cycles of combination chemotherapy and hormone replacement therapy and showed excellent response.

(J Bangladesh Coll Phys Surg 2008; 26: 97-99)

menstruation and absence of development of breasts till then. She gave no history of periodic lower abdominal pain, dysuria, frequency or retention of urine. She had no heat or cold intolerance, constipation and no significant weight loss, visual disturbance, trauma or tuberculosis. Her mother gave no history of relevant drug intake during pregnancy and she had no history of difficult labor during her birth or encephalitis in childhood. There was no family history of primary amenorrhea, tuberculosis or diabetes. She gave no significant drug, medical or surgical history.

She was examined thoroughly and general parameters were found normal. Her height was 5' 3", weight 52 $\mathrm{kg}$, \& had masculine type body built. She was depressed but co-operative. Her scalp hair was long, axillary \& pubic hair was well developed with female distribution. Her visual field was normal with normal color vision. She gave no history of anosomia \& had no bony abnormality. Her thyroid gland was not enlarged \& other lymph nodes were not palpable. Her breasts were not developed \& had widely spaced nipples. She had no stigmata of chromosomal or other endocrine diseases.

Her per abdominal examination revealed no palpable mass or abnormality. Pubic hair was well developed $\&$ female type in distribution. Vulva including labia majora, minora \& clitoris was well developed. No swelling was found in the inguinal region. Vaginal introitus was narrow \& per vaginal examination could not be done. Per rectal examination was done \& a nodular firm cord like structure was found in the midline at the apex of the examining finger.

All the relevant investigations were done. Her karyotype was 46XY with no structural or numerical 
abnormality of autosome. Her ultrasonography report showed no abnormality of the internal genital organs except that the uterus was smaller in size $(24 \mathrm{~mm} \mathrm{X}$ $12 \mathrm{~mm} \quad X \quad 24 \mathrm{~mm})$. Her general biochemical investigation report showed no abnormality. Hormone assays were done which showed low level of oestrogen \& testosterone \& high level of FSH \& LH. The value of oestrogen \& testosterone were 21.1 $\mathrm{pg} / \mathrm{ml} \& 44 \mathrm{ng} / \mathrm{ml}$ respectively. On the other hand the value of FSH \& LH were $87.40 \mathrm{IU} / \mathrm{L} \& 32.63 \mathrm{IU} / \mathrm{L}$ respectively. Her clinical diagnosis of primary amenorrhoea with gonadal dysgenesis was confirmed by these investigation reports. She was then properly counseled and Examination Under Anesthesia (EUA) \& laparoscopy was done on $25^{\text {th }}$ July, 2006. Laparoscopic examination revealed uterus smaller in size, mobile, anteverted. Cervix \& vaginal canal present \& normal. Both sided gonads were present, size of which were $2 \mathrm{~cm} \times 1 \mathrm{~cm} \times .5 \mathrm{~cm}$, surface irregular. Then laparotomy \& bilateral gonadectomy were done. Histopathology of the gonads showed a tumor composed of biphasic population of germ cells \& stromal cells, arranged in nests, areas of hyalinization and calcification present.

So, finally she was diagnosed as a case of primary amenorrhoea due to gonadal dysgenesis with gonadoblastoma. She was then referred to medical oncology department of the university where she received 6 cycles of combination chemotherapy as Bleomycin, Etioposite \& Cisplatin. Simultaneously she received hormone replacement therapy by conjugated equine oestrogen. Oestrogen was given in the dose of $.625 \mathrm{mg}$ daily for 21 days. In the last week of the cycle, progesterone was added in the dose of $5 \mathrm{mg}$ daily. She had withdrawal bleeding regularly \& start development of breasts after 3-6 months of hormone therapy. Her hormone therapy will be continued for at least 1 year to 3 years.

\section{Discussion:}

Primary amenorrhoea is defined as non establishment of menstruation. The case of primary amenorrhoea should be investigated by the age of 16 in presence of secondary sex characteristics \& by the age of 14 when there is no secondary sex characteristic ${ }^{5}$. For establishment of menstruation, 5 criteria must be fulfilled: i) she must be chromosomally competent female. ie 46XX karyotype. ii) hypothalamo pituitary ovary axis must be intact \& well functioning. iii) must have responsive endometrium. iv) must have patent outflow tract. v) active support from thyroid \& adrenal gland ${ }^{13}$.

Menstruation is the final result of a series of events which results in sexual maturity ${ }^{5}$. Maturation of the hypothalamo pituitary ovary through several years of late childhood begins a cascade of events which finally result in establishment of normal menstrual cycle \& menstruation. Amenorrhoea will result when there is defect or failure of function in any one of the organs involved in this cascade ${ }^{5}$.

Gonadoblastoma is a gonadal tumour \& is composed of combination of germ cells and sex cord stromal cells. This tumour occurs in sexually abnormal individuals, most commonly affected by gonadal dysgenesis and carrying the $\mathrm{Y}$ chromosome (i.e. $\mathrm{XY}$ gonadal dysgenesis or XO-XY mosaicism) ${ }^{4,7}$. Sometimes gonadoblastoma occurs in both phenotypically \& chromosomally normal females, even those with normal pregnancies 8,9 .

3 cases of gonadoblastoma were reported from a study, done in department of pathology, Tehran University in 1992. All were presented with primary Amenorrhoea.

24 year old patient with complete female phenotype with 46 XY Karyotyping \& small uterus \& fibrotic ovaries (Swyer Syndrome). Bilateral gonadectomy revealed features of gonadoblastoma.

19 years old girl with female phenotype with uterine agenesis with $85 \% 46 \mathrm{XY} \& 15 \% 46 \mathrm{XO}$ pattern. Bilateral small ovaries $(8 \mathrm{~mm})$ removed and showed gonadoblastoma.

19 years old girl with female phenotype with small infantile uterus $(3 \mathrm{~cm} \times 2 \mathrm{~cm} \times 5 \mathrm{~cm}), 46 \mathrm{XY}$ karyotype. Bilateral gonadectomy revealed gonadoblastoma overgrown by dysgerminoma.

So all patients with gonadoblastoma showed abnormal karyotype. It is bilateral in one-third cases 7. Hence all patients with primary amenorrhoea $\overline{\mathrm{e}}$ 46XY karyotype must be carefully counseled about the malignant potential of gonads $(30 \%)$. Gonadectomy must be done at a time when counseling is completed. Patients \& her guardians must be informed about the karyotyping \& nature of $\operatorname{gonad}^{5}$. 


\section{Conclusion:}

The exact incidence of gonadoblastoma is not known as poorer section of the community present to doctors for proper diagnosis \& management. It needs a lot of sophisticated investigations like karyotype, ultrasonography, hormone profile, sometimes laparoscopy, directed biopsy and histopathology. They need treatment by chemotherapy. All these investigations \& treatment are costly. So, for proper management, there should be cost effectiveness facilities in specialized centre at least in tertiary level hospitals.

Patients with pure gonadoblastoma have excellent prognosis provided both gonads have excised as gonadoblastoma have never been detected with metastatic lesion \& never occur outside the gonads 4,5. The prognosis of patients with gonadoblastoma associated with dysgerminoma is also good provided course of chemotherapy has strictly followed.

\section{Reference:}

1. Scully RE Gonadoblastoma. A review of 74 cases. cancer.1970 jun,25(6):1340-1350.

2. eMedicine-Gonadoblastoma: Article by Joseph L Lasky III, MD www.emedicine.com/ped/tepic882.htm-88k-cached
3. Gonadoblastoma: Information from answers.com www.answers.com/topic/gonadoblastoma-in-medicine-40kcached.

4. Current Obs \& Gynae diagnosis \& treatment, 8th edition, edited by Alaw H. Dccherthey, MD. Martin L Peonol MD. Page 320, 581

5. Dewheents textbook of obstetrics \& Gynaecology for post graduates, 6th edition, edited by D. Keith Edmonds, page 312-316

6. Chellam VG, Mathew A, Varghese S. Unilateral gonadoblastoma with dysgerninoma review \& report of case. Indian J Cancer. 1981 Jun, 18(2):163-166

7. Fisher RA, Salam R, Spencer RW. Bilateral gonadoblastoma/ dysgerminoma in a $46 \mathrm{XY}$ hormonal studies. J Clin Pathol. 1982 Apr; 35(4):420-424.

8. McDonough PG, Byrd JR, Tho PT, Otken L. Gonadoblastoma in true hermaphrodite obstet gyneclo. 1976 Mar; 47(3): 355-388

9. De Bacalao EB, Dominguez I. Unilateral gonadoblastoma in a pregnant woman. Am J obstet Gynecol.1969; Dec 15. 105(8); 1279-1281

10. Medical Journal, Department of Pathology, Tehran University, 1992.

11. Landis. SH, Murray T, Bolden S. Wingo PA. Cancer statistics, 1999. CA-A Cancer J Clin 1999. 49 (1) i:8

12. Jacobs IJ, Skates SJ, Mc Donald N, et al. Screening for ovarian cancer, a pilot randomized controlled trial, lancet. 1999; 353: 1207 